\title{
Potencial produtivo de novilhas da raça "Pantaneira" alimentadas com fenos de baixa qualidade
}

\section{Productive potential of heifers breed "Pantaneira" fed low-quality hay}

\author{
João Rufino Junior ${ }^{1 *}$; Marcus Vinicius Morais de Oliveira²; \\ Daniel Marino Guedes de Carvalho; ${ }^{3}$; Ana Lúcia Teodoro4; \\ Fernando Miranda de Vargas Junior ${ }^{5}$; \\ Rafael Henrique de Tonissi e Buschinelli de Góes ${ }^{5}$; Lilian Gasparetto Costa ${ }^{6}$
}

\begin{abstract}
Resumo
Os bovinos Pantaneiros são descendentes de um grupo genético europeu naturalizado no Bioma Pantanal e apesar de no passado dominarem a paisagem pantaneira, atualmente restam uma pequena centena de animais, o que coloca esta espécie em risco de extinção. Nesse sentido, este trabalho objetivou avaliar o desenvolvimento de novilhas da raça "Pantaneira", mantidas em regime de confinamento e alimentadas com fenos (Brachiaria brizantha cv. Piatã, Panicum maximum cv. Massai e Stylosantes capitatal macrocephala cv. Campo Grande) de baixa qualidade nutricional e ração concentrada, na proporção de $60: 40 \%$, respectivamente. Verificou-se que as forrageiras não influenciaram os comportamentos ingestivo e fisiológico, o consumo de matéria seca, o ganho de peso, o crescimento corpóreo, as concentrações séricas de glicose e ureia sanguínea e a perda de nitrogênio urinário, todavia, o feno de Piatã apresentou melhor digestibilidade aparente. Conclui-se que as novilhas apresentaram desenvolvimento satisfatório, com ganhos médios de $0,462 \mathrm{~kg} /$ dia e consumo de matéria seca de 2,13\% do peso corporal. Evidenciaramse assim, as características singulares desta raça em poder aproveitar forrageiras fibrosas e conseguir se desenvolver em ambientes que apresentem variações na qualidade nutricional dos volumosos, frequentemente notificados no Pantanal.
\end{abstract}

Palavras-chave: Conservação, desempenho, gado, ruminantes

\footnotetext{
Abstract

The cattle of breed "Pantaneira" are descended from a genetic group in the European naturalized on Pantanal Biome and although in the past dominating the landscape of the Pantanal, currently remains a small hundred of the animals, putting this species at risk of extinction. Thus, this study aimed to evaluate the development of heifers breed "Pantaneira", kept in confinement and fed with hay (Brachiaria brizantha cv. Piatã, Panicum maximum cv. Massai and Stylosantes capitata/macrocephala cv. Campo Grande)

${ }^{1}$ Zootecnista, Discente de doutorado em Agricultura Tropical, Universidade Federal do Mato Grosso, UFMT, Cuiabá, MT. E-mail: rufino@zootecnista.com.br

${ }^{2}$ Prof. Dr., Universidede estadual do Mato Grosso do Sul, UEMS, Aquidauana, MS. E-mail: marcusvmo@uems.br

${ }^{3}$ Prof. Dr., UFMT, Barras do Garça, MT. E-mail: danielguedes14@yahoo.com.br

${ }^{4}$ Zootecnista, Discente de Doutorado Produção Animal, Universidade Estadual de Maringá, UEM, Maringá, PR. E-mail: analuciazoo@yahoo.com.br

${ }^{5}$ Prof. Dr., Universidede Federal da Grande Dourados, UFGD, Dourados, MS. E-mail: fernandojunior@ufgd.edu.br, rafaelgoes@ ufgd.edu.br

${ }^{6}$ Médica Veterinária, Cuiabá, MS. E-mail: liliangasparetto@veterinaria.med.br

* Autor para correspondência
} 
of low quality nutritional and concentrate, in proportion of $60: 40 \%$, respectively. It was found that the forage did not affect ingestive and physiological behaviors, dry matter intake, weight gain, body growth, serum concentration of glucose and urea blood, and nitrogen urinary loss, however, the hay of Brachiaria brizantha presented better apparent digestibility. It is concluded that the heifers presented developed satisfactorily, with average gains of $0.462 \mathrm{~kg}$ /day and dry matter intake of $2.13 \%$ of corporal weight. Thus evidencing, the unique characteristics of this breed to be able to avail fibrous forage and succeed if develop in environments that present vary in nutritional quality of forages, commonly reported in the Pantanal.

Key words: Cattle, conservation, performance, ruminants

\section{Introdução}

Os bovinos da raça "Pantaneira" também conhecidos como Tucura são um recurso genético naturalizado no Pantanal Brasileiro, sendo originário da Península Ibérica (TEODORO, 2011). Nos Estados de Mato Grosso e Mato Grosso do Sul foram introduzidos no século XVI, durante o período de colonização, e se adaptaram as condições climáticas e nutricionais da região Pantaneira, reproduzindo e multiplicando-se sem interferência direta do homem (MAZZA et al., 1992). A seleção natural resultou num grupo genético rústico, prolífico e apto para sobreviver em condições de estresse hídrico e alimentar, apresentando índices de maior natalidade e menor mortalidade se comparadas com as raças zebuínas criadas atualmente no Pantanal (MAZZA et al., 1994; ABREU; MCMANNUS, 2000).

Apesar de reduzirem seu tamanho corporal, para se adaptarem às condições peculiares da planície pantaneira, os bovinos da raça "Pantaneira" ainda conservaram de seus ancestrais taurinos a elevada habilidade materna e longevidade (ABREU et al., 2007), produzindo animais férteis, precoces e sexualmente ativos, com partos normais e bezerros sadios (ABREU et al., 2004; SANTOS et al., 2005). Representam assim, uma interessante opção para a criação pecuária em regiões alagadas de maneira sustentável, pois são animais de alta rusticidade e com menor exigência nutricional (JULIANO et al., 2011).

Entre as características produtivas de interesse zootécnico, o ganho de peso é, sem dúvida, o mais pesquisado e o que mais diretamente se associa à produtividade de um rebanho. A conversão alimentar por outro lado, representa a eficiência com que o animal transforma o alimento ingerido em componentes corpóreos. No caso das planícies pantaneiras essas características são de suma importância, devido escassez de alimento no período de seca e ao estresse hídrico no período das enchentes, obrigando os animais a pastorearem em áreas alagadas (MAZZA et al., 1994). Ressaltase que nessas condições ambientais, os animais da raça "Pantaneira" se destacam, já que são os únicos bovinos capazes de pastejar forrageiras aquáticas (SERENO, 2002) e de suportarem por meses seguidos as condições de umidade constante nos cascos.

Nesse sentido, como as informações zootécnicas dos bovinos da raça "Pantaneira" são escassas, fazse necessário efetuar avaliações sobre o desempenho destes animais, bem como a real capacidade da raça em aproveitar forrageiras de baixa qualidade nutricional.

\section{Material e Métodos}

O experimento foi conduzido no Núcleo de Bovinos Pantaneiros de Aquidauana (NUBOPAN), pertencente à Universidade Estadual de Mato Grosso do Sul (UEMS), em Aquidauana, MS Brasil, região do Alto Pantanal Sul-Mato-Grossense, cujas coordenadas geográficas são: altitude $181 \mathrm{~m}$, latitude $20^{\circ} 28^{\prime} \mathrm{Sul}$ e longitude $55^{\circ} 47^{\prime}$ Oeste.

Foram utilizadas quinze novilhas, com idade média de 30 meses e peso corpóreo (PC) inicial médio de $298 \mathrm{~kg}$, mantidas em regime de confinamento por 114 dias, sendo os 30 primeiros para adaptação as instalações, ao manejo e a dieta, 
e os outros 84 para coleta dos dados, sendo este dividido, em três períodos de 28 dias.

No início do ensaio, as novilhas foram separadas em três lotes de cinco animais, num delineamento inteiramentecasualizadoeemseguida foramalocadas nos tratamentos contendo diferentes espécies forrageiras, numa relação volumoso:concentrado, de 60:40\%, respectivamente, na base da matéria seca. Como volumoso foram utilizados os fenos de braquiária cv. Piatã (Brachiaria brizantha); de capim colonião cv. Massai (Panicum maximum), e da leguminosa estilosantes cv. Campo Grande (Stylosantes capitata/macrocephala); sendo, portanto testadas duas gramíneas e uma leguminosa. Os fenos foram reduzidos a $\pm 3 \mathrm{~cm}$ de comprimento, utilizando-se um picador de forragem e aferidos com um Separador de Partículas de Forragem de Penn State. A ração concentrada era composta por milho, farelo de soja, sal mineral, ureia e calcário.

As dietas com teores energéticos e protéicos semelhantes, de 63,3\% de Nutrientes Digestíveis Totais (NDT) e 12,5\% de Proteína Bruta (PB), foram fornecidas duas vezes ao dia, às $7 \mathrm{~h} 00 \mathrm{e}$ às $16 \mathrm{~h} 00$, proporcionando sobra de aproximadamente $10 \%$, sendo a composição das dietas experimentais descritas na Tabela 1 .

Tabela 1. Composição percentual e química das dietas, com base na matéria seca.

\begin{tabular}{lccc}
\hline \multirow{2}{*}{ Ingredientes } & \multicolumn{3}{c}{ Dietas } \\
\cline { 2 - 4 } & Piatã & Massai & Estilosantes \\
\hline Feno de Piatã & 60,00 & - & - \\
Feno de Massai & - & 60,00 & - \\
Feno de Estilosantes & - & - & 60,00 \\
Grão de milho triturado & 27,00 & 26,60 & 32,30 \\
Farelo de soja & 11,50 & 11,90 & 06,20 \\
Ureia $_{\text {Sal mineral }^{1}}$ & 00,50 & 00,50 & 00,50 \\
Calcário calcítico $_{\text {Total }}$ & 00,80 & 00,80 & 00,80 \\
\hline Proteína bruta & 00,20 & 00,20 & 00,20 \\
Nutrientes digestíveis totais estimados & 100,00 & 100,00 & 100,00 \\
Fibra em detergente neutro & 12,60 & 12,60 & 12,50 \\
Fibra em detergente acido & 63,30 & 63,30 & 63,10 \\
\hline
\end{tabular}

${ }^{1}$ Cálcio: 120g; Fósforo: 88 g; Sódio: 132g; Enxofre: 12 g; Cobalto: 55 mg; Cobre: 1.530 mg; Cobre: 1.800 mg; Iodo: 75 mg; Manganês: $1.300 \mathrm{mg}$; Selênio: $15 \mathrm{mg}$; Zinco: $3.630 \mathrm{mg}$; Cromo: $10 \mathrm{mg}$; Flúor: $880 \mathrm{mg}$; Fosforilato base: $100 \mathrm{~g}$.

Fonte: Elaborado pelos autores.

As novilhas permaneceram confinadas num galpão de alvenaria, com pé direito de 4 metros e telhas de barro. As baias eram individuais com 2,2 x 4,0 m, providas de cocho e bebedouro automático, com laterais feitas com cordoalha de aço e $70 \%$ do piso revestido com concreto e $30 \%$ de terra coberta semanalmente com palha de arroz, para aumentar o conforto e eliminar a umidade. Antes de iniciar o período experimental os animais foram protegidos contra ecto e endoparasitos, e receberam uma dose intramuscular das vitaminas A, D e E.

O desempenho dos animais foi avaliado pesandose as novilhas em balança mecânica no início do experimento e posteriormente em intervalos de 28 dias, após jejum de sólidos de 12 horas. O ganho de peso total (GPT) foi determinado pela diferença entre os pesos final e inicial dos animais, enquanto 
que o ganho médio diário (GMD) foi determinado pela divisão do GPT pela quantidade de dias destinados a medição do desempenho, ou seja nos 84 dias. As determinações das alturas da cernelha e garupa foram realizadas utilizando-se um hipômetro nas mesmas datas das pesagens dos animais.

Os consumos de matéria seca (CMS), expressos em kg/dia, em percentagem do peso corpóreo ( $\mathrm{kg}$ de MS/100 kg PC) e em função do peso metabólico ( $\mathrm{g}$ de $\left.\mathrm{MS} / \mathrm{PC}^{0,75}\right)$, de proteína bruta (CPB), de fibra em detergente neutro (CFDN), de fibra em detergente ácido (CFDA), de extrato etéreo (CEE) e de matéria mineral (CMM) e a conversão alimentar (CA) foram determinados pesando-se diariamente os alimentos oferecidos e as sobras. As amostras referentes ao período de 28 dias, por animal, foram mantidas congeladas e posteriormente analisadas.

Para determinação da digestibilidade aparente dos nutrientes foi realizado no final de cada período experimental, por três dias consecutivos, uma coleta de amostra de fezes, de aproximadamente $300 \mathrm{~g}$, diretamente na ampola retal do animal, nos horários de $8 \mathrm{~h} 00,12 \mathrm{~h} 00$ e $16 \mathrm{~h} 00$ nos dias $26^{\circ}, 27^{\circ}$ e $28^{\circ}$, respectivamente. Imediatamente após a coleta, as amostras de fezes foram acondicionadas em sacos plásticos, identificadas e congeladas.

As amostras dos alimentos ofertados, sobras e fezes foram analisadas, determinando-se os teores de matéria seca (MS), proteína bruta $(\mathrm{PB})$, matéria mineral (MM), fibra em detergente neutro (FDN), fibra em detergente ácido (FDA) e extrato etéreo (EE).

As concentrações de fibra em detergente neutro indigestível (FDNi) foram determinadas por intermédio da digestibilidade in situ, obtida após incubação por 240 horas, segundo o método descrito por Casali et al. (2008). As amostras foram moídas em peneira de $1 \mathrm{~mm}$ e incubadas em sacos de TNT (tecido não tecido) de $6 \times 6 \mathrm{~cm}$. A matéria orgânica (MO) foi estimada pela diferença entre 100 e a porcentagem de matéria mineral (MM), segundo equação: $\mathrm{MO}(\% \mathrm{MS})=100-\mathrm{MM}(\% \mathrm{MS})$.
Os teores de Carboidratos Totais (CT) foram determinados pela equação: $\mathrm{CT}=\{100-[\mathrm{PB}(\% \mathrm{MS})$ $+\mathrm{EE}(\% \mathrm{MS})+\mathrm{MM}(\% \mathrm{MS})]\}$ e os Nutrientes Digestíveis Totais calculados a partir da equação: NDT $(\mathrm{g} /$ dia $)=\{($ PB ingerida - PB fezes $)+($ CHOT ingerido - CHOT fezes $)+[2,25 \times$ (EE ingerido - EE fezes $)]\}$, propostas por Sniffen et al. (1992). Os Carboidratos Não Fibrosos (CNF) foram determinados de acordo com a equação: $\mathrm{CNF}=\{100-[[\mathrm{PB}(\% \mathrm{MS})-\% \mathrm{~PB}$ derivada da ureia $+\%$ de ureia] + FDN $(\% \mathrm{MS})+\mathrm{EE}$ $(\% \mathrm{MS})+\mathrm{MM}(\% \mathrm{MS})]\}$.

A estimativa da produção fecal (EF) foi realizada utilizando-se a fibra em detergente neutro indigerível (FDNi) como indicador interno, segundo equação: $\mathrm{EF}(\mathrm{kg} \mathrm{MS} /$ dia $)=($ FDNi consumida $(\mathrm{g}) /$ FDNi fecal $(\mathrm{g} / \mathrm{kg})$ ), onde FDNi consumida = FDNi ingerido $(\mathrm{kg} /$ dia) e FDNi fecal = Concentração de FDNi nas fezes ( $\mathrm{g} / \mathrm{kgMS}$ ). Para isto, foram incubados os alimentos oferecidos, as sobras e as fezes $(0,5 \mathrm{~g}$ de amostra moída em peneira de $1 \mathrm{~mm}$ em cada saco de $5 \times 5 \mathrm{~cm}$ confeccionado de TNT (Tecido Não Tecido - 100g/ $\left.\mathrm{m}^{2}\right)$ ) no rúmen de um boi mestiço por 144 horas, sendo estes sacos posteriormente lavados em água corrente e, em seguida, procedeu-se a determinação do FDNi.

Os consumos de matéria seca total (CMST) e matéria seca de nutrientes (CMSNut) foram estimados pela diferença entre a quantidade de alimentos fornecida e quantidade de sobras, através das equações: CMST $(\mathrm{kg} /$ dia $)=$ Matéria seca ofertada (kg) - Matéria seca sobras (kg) e CMSNut $(\%)=($ MS ingerida $\mathrm{x} \%$ do Nutriente $)-($ MS sobras $\mathrm{x} \%$ Nutriente). Os coeficientes de digestibilidade aparente dos nutrientes (DAN) foram estimados pela equação: DAN $(\%)=[((\mathrm{MS}$ ingerida $\mathrm{x} \%$ Nutriente) - (MS excretada $x \%$ Nutriente) / (MS ingerida $\mathrm{x} \%$ Nutriente)) $\mathrm{x} 100]$.

No $27^{\circ}$ dia experimental de cada período, realizou-se coleta de sangue via veia jugular, quatro horas após a alimentação, em tubos de ensaio contendo 2 gotas de heparina para impedir a coagulação do sangue. As amostras foram 
imediatamente centrifugadas e o plasma congelado; sendo posteriormente, realizada as análises de creatinina e ureia utilizando-se kits comerciais $L a b$ Test, com leitura feita em espectrofotômetro. No $26^{\circ}$ dia experimental de cada período, efetuou-se coleta de urina (CHIZZOTTI et al., 2008), na forma "spot" quatro horas após a alimentação, através de massagem da região perineal. As amostras de urina foram diluídas em ácido sulfúrico a $0,018 \mathrm{~N}, 10 \mathrm{~mL}$ para $40 \mathrm{~mL}$, respectivamente e congeladas, sendo posteriormente determinada as concentrações de creatinina e ureia. A estimativa da excreção urinária (EU) foi realizada através da equação proposta por Rennó (2003): EU (litros/dia) $=[(27,77$ mg creatinina x Peso corpóreo) / Concentração de creatinina na amostra em $\mathrm{mg} / \mathrm{litro}]$.

A excreção de ureia na urina, expressa em g/ dia, $\mathrm{mg} / \mathrm{kgPV}$ e mg N-ureia/kgPV, foram estimadas pelas respectivas equações: $\{[(\mathrm{mg} / \mathrm{dl}$ de ureia na amostra de urina x 10) x litros de urina] / 1000\}, [(mg/dia de ureia) / peso corpóreo] e ( $\mathrm{mg} / \mathrm{kg}$ de peso corpóreo de ureia x 0,466).

As análises estatísticas foram conduzidas em um delineamento inteiramente casualizado, segundo o modelo estatístico: $\mathrm{Y}_{\mathrm{ij}}=\mu+\mathrm{t}_{\mathrm{i}}+\mathrm{e}_{\mathrm{ij}}$, em que $\mu=$ constante geral; $t_{i}=$ efeito do suplemento $i$, sendo $\mathrm{i}=1,2,3$ e $4 ; \mathrm{e}_{\mathrm{ij}}=$ erro aleatório, associado a cada observação, pressupostoNID $\left(0, \sigma^{2}\right)$.

O comportamento ingestivo e fisiológico foi avaliado através de observações efetuadas em intervalos de cinco minutos, durante três períodos de 48 horas, num total de 144 horas. Os parâmetros avaliados para comportamento ingestivo foram Ruminando em Pé (RP), Ruminando Deitado (RD), Ócio em Pé (OP), Ócio Deitado (OD), Dormindo (DOR), Comendo (CO) e Interagindo (INT). Já os parâmetros avaliados para comportamento fisiológicos foram o número de vezes que os animais realizaram a ingestão de água, a defecação e o ato de urinar.

A eficiência de alimentação e ruminação em função da MS, FDN e PB foram calculadas de acordo com as seguintes equações adaptadas de Marques (2008), onde: EAMS = CMS/TA $(\mathrm{kg}$ $\mathrm{MS} / \mathrm{h}$ ) - Eficiência de Alimentação em função do CMS; ERMS = CMS/TR (kg MS/h) - Eficiência de Ruminação em função do CMS; EAFDN = CFDN/TA (kg FDN/h) - Eficiência de Alimentação em função do CFDN; ERFDN = CFDN $/ \mathrm{TR}(\mathrm{kg}$ FDN/h) - Eficiência de Ruminação em função do $\mathrm{CFDN}$; EAPB = CPB/TA (kg PB/h) - Eficiência de Alimentação em função do CPB; ERPB = CPB/TR ( $\mathrm{kg} P B / h)$ - Eficiência de Ruminação em função do CPB; sendo: CMS (kg MS/dia) - Consumo de matéria seca; TA (h/dia) - Tempo de Alimentação; TR (h/dia) - Tempo de Ruminação Total; CFDN (kg FDN/dia) - Consumo de Fibra em Detergente Neutro e CPB (kg PB/dia) - Consumo de Proteína Bruta.

Os dados foram analisados por meio de análise de variância, sendo em cada respectivo parâmetro utilizada a sua própria co-variável para eliminar o efeito que esta exerce sobre a variável avaliada. Para comparações entre médias, adotou-se o teste de Tukey, ao nível de probabilidade de 5\%.

\section{Resultados e Discussão}

As forrageiras não influenciaram significativamente $(\mathrm{P}>0,05)$ o desempenho das novilhas da raça "Pantaneira" (Tabela 2), as quais apresentaram peso corpóreo inicial e final médio de 298,10 e $336,90 \mathrm{~kg}$, respectivamente; sendo o peso final correspondente a $96,30 \%$ do peso médio de vacas adultas nas condições pantaneiras, que é próximo de $350 \mathrm{~kg}$. 
Tabela 2. Desempenho de novilhas da raça "Pantaneira" submetidas a tratamentos com diferentes tipos de fenos, com os respectivos erros padrões e média geral.

\begin{tabular}{|c|c|c|c|c|c|}
\hline \multirow{2}{*}{ Variáveis $^{1}$} & \multicolumn{3}{|c|}{ Fenos } & \multirow{2}{*}{$\begin{array}{c}\text { Erro } \\
\text { Padrão } \\
\end{array}$} & \multirow{2}{*}{ Média } \\
\hline & Piatã & Massai & Estilosantes & & \\
\hline Peso corporal inicial $(\mathrm{kg})$ & $300,7 \pm 40,2$ & $295,0 \pm 36,8$ & $298,6 \pm 18,1$ & 6,63 & 298,1 \\
\hline Peso corpóreo final (kg) & $341,8 \pm 50,5$ & $331,6 \pm 49,3$ & $337,2 \pm 26,1$ & 8,54 & 336,9 \\
\hline Ganho de peso médio diário $(\mathrm{kg})$ & $0,489 \pm 0,155$ & $0,436 \pm 0,181$ & $0,460 \pm 0,151$ & 0,36 & 0,46 \\
\hline Conversão alimentar & $15,55 \pm 6,28$ & $15,68 \pm 4,07$ & $15,08 \pm 4,81$ & 1,02 & 15,44 \\
\hline Altura de cernelha inicial (m) & $1,19 \pm 0,06$ & $1,19 \pm 0,04$ & $1,22 \pm 0,03$ & 0,93 & 1,20 \\
\hline Ganho em altura de cernelha (m) & $0,03 \pm 0,02$ & $0,02 \pm 0,01$ & $0,02 \pm 0,02$ & 0,33 & 0,02 \\
\hline Altura de garupa inicial (m) & $1,24 \pm 0,06$ & $1,25 \pm 0,03$ & $1,26 \pm 0,02$ & 0,80 & 1,25 \\
\hline Ganho em altura de garupa (m) & $0,02 \pm 0,02$ & $0,02 \pm 0,01$ & $0,01 \pm 0,01$ & 0,25 & 0,02 \\
\hline
\end{tabular}

${ }^{1}$ Médias na linha são estatisticamente iguais de acordo com o teste Tukey ao nível de $5 \%$ de probabilidade.

Fonte: Elaborado pelos autores.

O ganho de peso médio diário, de 460 gramas, pode ser considerado satisfatório para a raça, já que este grupamento genético nunca passou por nenhum tipo de seleção aprimorada e/ou de melhoramento genético pelo homem (MAZZA et al., 1994), possuindo um frame pequeno (ABREU et al., 2004) e crescimento lento, porém contínuo (ABREU; MCMANNUS, 2000). Teodoro (2011) ao avaliar o desempenho de novilhas pantaneiras, dos 18 aos 22 meses de idade, em regime de confinamento, observou ganhos de 570g/dia, podendo esse menor desempenho ser atribuído a maior idade e, consequentemente, a menor capacidade de converter os alimentos ingeridos em tecido corpóreo. Segundo Rubiano (2006), animais jovens transformam mais eficientemente os alimentos ingeridos em tecidos ósseo e muscular, enquanto que animais mais próximos de seu peso adulto essa transformação e quase totalmente direcionada para deposição de gordura; além disso, quanto maior o tamanho corporal de um grupo genético, maior o seu ganho de peso diário.

Os diferentes volumosos também não influenciaram $(\mathrm{P}>0,05)$ o consumo de matéria seca e a conversão alimentar (Tabelas 2 e 3), apresentando médias de $2,13 \%$ do peso corporal e 15,44 kg/kg, respectivamente. Teodoro (2011) ao alimentar bovinos pantaneiros, com diferentes níveis de proteína na dieta, variando de 11 a $17 \%$ de $\mathrm{PB}$, verificou apenas diferenças numéricas e não significativas no consumo de matéria seca e na conversão alimentar, com médias de 2,81\% do peso corporal e 10,95 kg/kg, respectivamente.

Cabral et al. (2006) ao alimentarem bovinos nelore, com peso corpóreo de $351 \mathrm{~kg}$, com $90 \%$ de feno de tífton (Cynodon dactylon) e 10\% de ração concentrada, observaram ingestões de $5,75 \mathrm{~kg}$ de $\mathrm{MS} /$ animal/dia, portanto, inferior ao valor de $6,77 \mathrm{~kg}$ encontrado neste experimento (Tabela 3). Por outro lado, Silva et al. (2010) trabalhando com diferentes suplementos para novilhos da raça Nelore, a pasto, com peso inicial médio de $373,70 \mathrm{~kg}$ e 26 meses de idade, observaram consumo de 7,92 kg de MS/animal/ dia no período seco, portanto superior ao verificado neste trabalho. Detmann et al. (2003), em revisão de 45 artigos sobre bovinos de diferentes grupamentos genéticos e alimentados com forrageiras tropicais, encontraram valor médio de consumo de matéria seca de 3,44; 2,30 e 2,15\% do peso vivo, para animais mestiços, europeus e zebuínos, respectivamente; sendo estes valores próximos ao encontrado neste ensaio. 
Tabela 3. Consumos de matéria seca e de nutrientes em novilhas da raça "Pantaneira" recebendo diferentes tipos de fenos.

\begin{tabular}{|c|c|c|c|c|c|c|}
\hline \multirow{2}{*}{ Variáveis ${ }^{1}$} & \multicolumn{3}{|c|}{ Forrageiras } & \multirow{2}{*}{$\begin{array}{c}\text { Erro } \\
\text { Padrão }\end{array}$} & \multirow{2}{*}{$\mathrm{CV}$} & \multirow{2}{*}{ Média } \\
\hline & Piatã & Massai & Estilosantes & & & \\
\hline Matéria seca (kg) & 7,11 & 6,60 & 6,61 & 0,28 & 15,92 & 6,77 \\
\hline CMSPC (kg MS/100 kg PC) & 2,22 & 2,10 & 2,08 & 0,79 & 14,40 & 2,13 \\
\hline CMSPM $\left(\mathrm{g}\right.$ MS/PC $\left.{ }^{0,75}\right)$ & 93,86 & 88,42 & 87,92 & 3,30 & 14,19 & 90,07 \\
\hline Proteína bruta (kg) & 1,21 & 1,10 & 1,07 & 1,13 & 15,51 & 1,13 \\
\hline Fibra detergente neutro $(\mathrm{kg})$ & 3,40 & 3,13 & 2,88 & 3,14 & 20,31 & 3,14 \\
\hline Fibra detergente ácido (kg) & 1,76 & 1,66 & 1,79 & 1,74 & 18,29 & 1,74 \\
\hline Carboidratos totais $(\mathrm{kg})$ & 5,42 & 5,06 & 5,16 & 5,21 & 16,56 & 5,21 \\
\hline Carboidratos não fibrosos (kg) & 4,07 & 4,00 & 3,56 & 3,88 & 10,31 & 3,88 \\
\hline Extrato etéreo (kg) & 0,16 & 0,16 & 0,17 & 0,16 & 11,16 & 0,16 \\
\hline Matéria mineral (kg) & $0,32 \mathrm{a}$ & $0,28 \mathrm{ab}$ & $0,21 \mathrm{~b}$ & 0,27 & 19,05 & 0,27 \\
\hline Nutrientes digestíveis totais $(\mathrm{kg})$ & $3,69 \mathrm{a}$ & $3,29 \mathrm{~b}$ & $3,07 \mathrm{~b}$ & 3,35 & 4,61 & 3,35 \\
\hline
\end{tabular}

${ }^{1}$ Médias seguidas de letras diferentes, na linha, diferem entre si $(\mathrm{P}<0,05)$ pelo teste Tukey.

Fonte: Elaborado pelos autores.

Também não foram observadas diferenças significativas $(\mathrm{P}>0,05)$ de conversão alimentar com média de $15,44 \mathrm{~kg} / \mathrm{kg}$ (Tabela 2), sendo esta, $41 \%$ superior à conversão observada por Teodoro (2011), que foi de 10,95, para novilhas da raça "Pantaneira" em fase de crescimento. Essa piora na eficiência de transformação de nutrientes alimentares, em tecido corpóreo, pode ser compreendida pelo próprio avanço da idade dos animais, e pela capacidade dos bovinos pantaneiros em ingerir alimentos altamente fibrosos, em especial forragens de baixa qualidade nutricional.

Cavalcante et al. (2005) ao fornecerem a novilhos zebuínos não castrados, com peso corpóreo de 398,40 kg, dietas constituídas de $65 \%$ de feno de capim Tifton 85 (Cynodon dactylon sp.) e $35 \%$ de concentrado, verificaram conversão alimentar de 10,01. Já Faturi et al. (2006) e Dian et al. (2009) ao trabalharem com mestiços $1 / 2$ Nelore x $1 / 2$ Angus, não castrados, com 18 meses de idade, observaram conversões alimentares de 7,99 e 6,22 , respectivamente. Esse maior aproveitamento dos nutrientes dietéticos pode ser explicado pelo potencial genético dessas raças, que ao longo dos anos vem sendo constantemente melhorado pelo homem para produção de carne.

Em relação aos ganhos médios de cernelha e de garupa (Tabela 2) infere-se que as diferentes forrageiras também não afetaram significativamente estas variáveis, com médias de 2,0 e 2,0 cm, respectivamente. Todavia, como os bovinos pantaneiros apresentam uma baixa estatura, considera-se satisfatória a altura dos animais, de 120 e 125 centímetros para cernelha e garupa, respectivamente, sendo estes valores próximos a estatura de um animal adulto.

Neste ensaio, os consumos de proteína bruta (PB), fibra em detergente neutro (FDN), de fibra em detergente ácido (FDA), carboidratos totais (CT), carboidratos não fibrosos (CNF) e extrato etéreo (EE), expressos em quilograma, não foram influenciados significativamente pelos tratamentos testados, com respectivas médias de 1,13, 3,14, 1,74, 5,21, 3,88 e 0,16 kg/animal/dia (Tabela 3). Já o consumo de matéria mineral (MM) em kg/ dia e expresso em percentagem do peso corpóreo, foi influenciado $(\mathrm{P}<0,05)$ pela forrageira, sendo observada maior ingestão nos animais que receberam a Brachiaria brizantha cv. Piatã, (0,32 kg/dia), em 
relação ao Stylosantes capitata/macrocephala cv. Campo Grande $(0,21 \mathrm{~kg} / \mathrm{dia})$. Essa diferença no consumo da fração mineral pode ser compreendida ao observar a concentração deste nutriente na forrageira, apresentando o feno de Estilosantes uma concentração mineral $36,7 \%$ inferior ao feno de Piatã. O consumo de Nutrientes Digestíveis Totais (NDT) também foi superior $(\mathrm{P}<0,05)$, para o tratamento contendo feno de Piatã em relação aos fenos de Massai e Estilosantes, devido à maior digestibilidade dos nutrientes dessa forrageira, que pode ser observado na (Tabela 3 ).

Consumos de PB e FDN inferiores, de 0,75 e 2,49 $\mathrm{kg} /$ animal/dia, respectivamente, foram observados por Silva et al. (2006) ao alimentarem novilhos nelore, com peso corpóreo médio de $299 \mathrm{~kg}$, com dietas contendo $11 \%$ de PB baseadas em silagens de sorgo e de milho; podendo as diferenças serem explicadas pelo fato da menor concentração de PB e FDN nas dietas por eles testadas. Consumo de FDN semelhante ao presente trabalho, de $3,22 \mathrm{~kg} /$ animal/ dia, foi verificado por Ribeiro et al. (2001) ao fornecerem feno de Tífton (Cynodon dactylon sp.) a novilhos zebuínos. Ítavo et al. (2002) observaram em novilhos nelore, não castrados, com peso corporal de $240 \mathrm{~kg}$ e alimentados com feno de capim-Tifton 85 (Cynodon sp.), consumo de FDA de 1,72 kg/ animal/dia, e portanto, similar ao encontrado neste ensaio. Já Teodoro (2011), observou em novilhas pantaneiras confinadas consumos médios de $\mathrm{PB}$, FDN, FDA, EE e MM de 0,74, 2,78, 1,50, 0,07 e $0,29 \mathrm{~kg} /$ animal/dia, respectivamente e, portanto, inferiores a este ensaio.

Neste trabalho, o consumo médio de FDN, de $0,98 \%$ do peso corporal, está dentro do preconizado por Mertens (1992), o qual sugeriu não ultrapassar $1,20 \%$, por ocasionar redução no consumo de matéria seca e, consequentemente, dos outros nutrientes. Está também coerente com os valores preconizados por Detmann et al. (2003), que citaram ingestões máximas de 1,05 kg de FDN/100 $\mathrm{kg}$ de peso corporal para bovinos em crescimento alimentados com forrageiras tropicais. Segundo esses mesmos autores, animais zebus, europeus e mestiços consomem em média 0,99, 1,04 e 1,15 $\mathrm{kg}$ de FDN/100kgPC, corroborando-se, portanto, a afirmativa de que os bovinos da raça "Pantaneira" possuem um consumo similar a outras raças europeias.

A digestibilidade aparente da matéria seca, matéria orgânica, proteína bruta e carboidratos totais foram maiores para os animais alimentados com feno de Piatã, não havendo, no entanto, diferenças na digestibilidade das variáveis carboidratos não fibrosos e matéria mineral, e nem nas concentrações dietéticas de NDT e Energia Digestível (Tabela 4).

Ribeiro et al. (2001), utilizando feno de capim Tifton (Cynodon dactylon sp.) com diferentes idade de corte obtiveram valores médios de digestibilidade aparente de 70,87, 72,62 e 74,4 para as variáveis MS, MO e CT, sendo estes valores superiores aos obtidos no presente trabalho. Embora esses autores tenham trabalhado com a mesma proporção de concentrado $(40 \%)$ nas dietas, as diferenças na digestibilidade da MS podem ser atribuídas ao melhor valor nutritivo dos fenos. Corroborando, Pereira et al. (2005), encontraram valores de digestibilidade aparente de 68,96, 70,18 e 69,46 para MS, MO e CT, respectivamente, em vacas leiteiras. Neste trabalho, o consumo de CNF não apresentou diferenças significativas entre os tratamentos $(\mathrm{P}>0,05)$, com média de $88,67 \%$ e próximo ao descrito por Pereira et al. (2005), cujos valores foram de $85,80 \%$.

Já a digestibilidade da fibra em detergente ácida foi inferior para a dieta contendo a leguminosa Estilosantes, podendo ser explicado devido à menor concentração de FDA nos fenos de Piatã e Massai tornando-os mais digestíveis. Por outro lado, a digestibilidade da fibra em detergente neutro foi estatisticamente diferente entre as forrageiras avaliadas, com maior aproveitamento do Piatã, seguido pelo Massai e Estilozantes (Tabela 4). Silva et al. (2010), trabalhando com pastagem tropical na época da seca para novilhos, encontraram digestibilidade de $56,76 \%$ da FDN. 
Ribeiro et al. (2001) trabalhando com feno de capim Tifton observou digestibilidade de 64,37\% da FDN e Teodoro (2011), observou em novilhas pantaneiras confinadas, digestibilidade de $41,25 \%$ da FDN sendo ambos os resultados superiores aos encontrados neste ensaio.

Tabela 4. Coeficiente de digestibilidade aparente da matéria seca, orgânica e nutrientes para novilhas da raça "pantaneira" consumindo fenos de baixa qualidade.

\begin{tabular}{|c|c|c|c|c|c|c|}
\hline \multirow{2}{*}{ Digestibilidade (\%)' } & \multicolumn{3}{|c|}{ Forrageiras } & \multirow{2}{*}{$\begin{array}{c}\text { Erro } \\
\text { Padrão }\end{array}$} & \multirow{2}{*}{$\mathrm{CV}$} & \multirow{2}{*}{ Médic } \\
\hline & Piatã & Massai & Estilosantes & & & \\
\hline Matéria seca & $52,81 \mathrm{a}$ & $42,97 \mathrm{~b}$ & $39,46 \mathrm{~b}$ & 0,68 & 5,86 & 45,08 \\
\hline Matéria orgânica & $55,01 \mathrm{a}$ & $46,28 \mathrm{~b}$ & $41,68 \mathrm{~b}$ & 0,71 & 5,79 & 47,66 \\
\hline Proteína bruta & $66,49 \mathrm{a}$ & $60,44 \mathrm{~b}$ & $55,28 \mathrm{~b}$ & 0,81 & 5,14 & 60,74 \\
\hline Extrato etéreo & 78,64 a & $69,71 \mathrm{ab}$ & $68,51 \mathrm{~b}$ & 1,44 & 7,74 & 72,29 \\
\hline Carboidratos totais & $51,71 \mathrm{a}$ & $42,40 \mathrm{~b}$ & $38,02 \mathrm{~b}$ & 0,70 & 6,17 & 44,05 \\
\hline Carboidratos não fibrosos & 90,48 & 87,01 & 88,55 & 0,75 & 3,27 & 88,67 \\
\hline Fibra detergente neutro & $35,55 \mathrm{a}$ & $25,10 \mathrm{~b}$ & $08,90 \mathrm{c}$ & 0,92 & 15,38 & 23,18 \\
\hline Fibra detergente ácido & $34,50 \mathrm{a}$ & $29,48 \mathrm{a}$ & $09,43 \mathrm{~b}$ & 0,96 & 15,23 & 24,47 \\
\hline Matéria mineral & 14,91 & 13,75 & 16,16 & 2,87 & 74,50 & 14,94 \\
\hline Nutrientes digestíveis totais $\left(\%{ }^{2}\right)$ & 52,75 & 52,08 & 51,11 & 13,20 & 7,32 & 51,98 \\
\hline Energia digestível (kcal/gMS $)$ & 2,33 & 2,30 & 2,25 & 14,56 & 8,01 & 2,29 \\
\hline
\end{tabular}

${ }^{1}$ Médias seguidas de letras diferentes, na linha, diferem entre si $(\mathrm{P}<0,05)$ pelo teste Tukey.

${ }^{2,3}$ NDT: ((Consumo NDT / Consumo de MS) * 100); ED: ((\%NDT/100) * 4,409), respectivamente.

Fonte: Elaborado pelos autores.

Neste trabalho, as dietas não proporcionaram diferenças significativas $(\mathrm{P}>0,05)$, para as concentrações de glicose e ureia no plasma sanguíneo, com valores médios respectivos, de 71,03 e 6,71 mg/dl (Tabela 5); e, portanto, inferiores aos encontrados por Franzolin, Silva e Ocampos(2001)em bubalinos, cujos valores foram de 82,47 e 7,35 mg/dl, respectivamente. Rennó et al. (2008), encontraram níveis de 14,54 mg/ dl de ureia plasmática em bovinos da raça holandesa. Já Oliveira et al. (2005) observaram em novilhas da raça holandesa concentrações plasmáticas de glicose de $85,55 \mathrm{mg} / \mathrm{dl}$.

Tabela 5. Valores de glicose e ureia sanguínea, perda de ureia através da urina em novilhas raça "Pantaneira" recebendo diferentes forrageiras, com os respectivos erros padrões e média geral.

\begin{tabular}{|c|c|c|c|c|c|c|}
\hline \multirow{2}{*}{ Variáveis $^{1}$} & \multicolumn{3}{|c|}{ Forrageiras } & \multirow{2}{*}{ Erro Padrão } & \multirow{2}{*}{$\mathrm{CV}$} & \multirow{2}{*}{ Média } \\
\hline & Piatã & Massai & Estilosantes & & & \\
\hline Glicose (mg/dl) & 70,07 & 72,56 & 70,47 & 19,56 & 8,18 & 71,03 \\
\hline Ureia $(\mathrm{mg} / \mathrm{dl})$ & 6,84 & 6,66 & 6,62 & 21,85 & 10,01 & 6,71 \\
\hline Ureia (g/dia) & 109,75 & 99,51 & 101,32 & 30,97 & 20,78 & 103,53 \\
\hline Ureia $(\mathrm{mg} / \mathrm{kgPC})$ & 369,53 & 312,29 & 310,66 & 49,98 & 26,40 & 330,83 \\
\hline N-ureia $(\mathrm{mg} / \mathrm{kgPC})$ & 173,95 & 145,53 & 144,77 & 44,46 & 24,31 & 154,75 \\
\hline
\end{tabular}

${ }^{1}$ Médias na linha são estatisticamente iguais de acordo com o teste Tukey ao nível de $5 \%$ de probabilidade.

Fonte: Elaborado pelos autores. 
Quanto a excreção de nitrogênio urinário, nas formas de ureia e N-ureico, foram também estatisticamente semelhantes com médias de 330,83 e de $154,75 \mathrm{mg} / \mathrm{kgPC}$, respectivamente (Tabela 5). Rennó et al. (2008), trabalhando com bovinos holandeses, cruzados e zebuínos observaram níveis de $350,5 \mathrm{mg} / \mathrm{kgPC}$ de ureia na urina e, portanto semelhante ao encontrado neste trabalho. Já Barbosa et al. (2006) trabalhando com diferentes categorias animais e diferentes níveis de concentrado, observaram concentração de 306,02 e 209,01 mg/
$\mathrm{kgPC}$ de ureia na urina em novilhas recebendo $50 \mathrm{e}$ $25 \%$ de concentrado, respectivamente.

Também não foram observadas diferenças significativas $(\mathrm{P}>0,05)$ de comportamento ingestivo, fisiológico, eficiência alimentar e eficiência ruminal, apresentando tempo médio de alimentação, ruminação e ócio de 232, 439 e $422 \mathrm{~min} /$ dia, respectivamente (Tabela 6). Teodoro (2011), observando as mesmas variáveis em novilhas pantaneiras, encontrou valores de 335, 472 e $362 \mathrm{~min} /$ dia para tempo médio de alimentação, ruminação e ócio.

Tabela 6. Comportamento ingestivo e fisiológico médio de novilhas da raça "Pantaneira" alimentadas com fenos de baixa qualidade.

\begin{tabular}{lccccc}
\hline \multirow{2}{*}{\multicolumn{1}{c}{ Variáveis $^{1}$}} & \multicolumn{3}{c}{ Forrageiras } & \multirow{2}{*}{ CV } & \multirow{2}{*}{ Média } \\
\cline { 2 - 4 } & Piatã & Massai & Estilosantes & & \\
\hline Tempo de alimentação (Min/dia) & 233,50 & 222,83 & 240,33 & 19,40 & 232,22 \\
Tempo de ruminação (Min/dia) & 446,83 & 409,50 & 460,67 & 7,88 & 439,00 \\
Tempo de ócio (Min/dia) & 430,00 & 455,67 & 381,67 & 14,40 & 422,44 \\
Tempo interagindo (Min/dia) & 177,83 & 167,33 & 173,17 & 17,26 & 172,78 \\
Tempo dormindo (Min/dia) & 155,17 & 184,67 & 184,17 & 25,81 & 174,67 \\
\hline & \multicolumn{5}{c}{ Eficiência de alimentação e ruminação } \\
EALMS / ERMS (kg MS/h) & $1,89 / 0,95$ & $1,78 / 0,97$ & $1,66 / 0,86$ & $13,0 / 14,8$ & $1,8 / 0,9$ \\
EALPB / ERPB (kg PB/h) & $0,32 / 0,16$ & $0,29 / 0,16$ & $0,26 / 0,14$ & $20,3 / 12,8$ & $0,3 / 0,1$ \\
EALFDN / ERFDN (kg FDN/h) & $0,92 / 0,45$ & $0,84 / 0,45$ & $0,72 / 0,38$ & $24,0 / 16,8$ & $0,8 / 0,4$ \\
\hline & \multicolumn{5}{c}{ Comportamento fisiológico } \\
Ingestão de água (n ${ }^{\circ}$ de vezes/dia) & 8,67 & 7,07 & 7,03 & 39,32 & 7,59 \\
Excreção de urina (n ${ }^{\circ}$ de vezes/dia) & 8,20 & 5,73 & 5,27 & 19,85 & 6,40 \\
Excreção de fezes (n ${ }^{\circ}$ de vezes/dia) & 9,43 & 7,80 & 6,67 & 30,57 & 7,97 \\
\hline
\end{tabular}

${ }^{1}$ Médias na linha são estatisticamente iguais de acordo com o teste Tukey ao nível de $5 \%$ de probabilidade.

${ }^{2}$ EALMS e ERMS: Eficiências de alimentação e ruminação em função do consumo de matéria seca; EAPB e ERPB: Eficiência de alimentação e ruminação em função do consumo de proteína bruta; EAFDN e ERFDN: Eficiência de alimentação e ruminação em função do consumo de fibra em detergente neutro.

Fonte: Elaborado pelos autores.

As forrageiras testadas não influenciaram o consumo, o ganho de peso diário, crescimento corpóreo e comportamento ingestivo e fisiológico de novilhas da raça "Pantaneira".

O feno de Brachiaria brizantha cv. Piatã apresentou a melhor digestibilidade aparente.

\section{Agradecimentos}

Ao Centro de Pesquisa do Pantanal (CPP) pelo financiamento da pesquisa e a CAPES pela concessão da bolsa de estudos. 


\section{Referências}

ABREU, U. G. P.; COBUCI, J. A.; SILVA, M. V. G. B.; SERENO, J. R. B. Uso de modelos no lineales para el ajuste de la curva de crecimiento de bovinos Pantaneiros. Archivos de Zootecnia, Córdoba, v. 53, n. 204, p. $367-$ 370, 2004.

ABREU, U. G. P.; MCMANNUS, C. Conservation of pantaneiro cattle. In: GLOBAL CONFERENCE ON CONSERVATION OF DOMESTIC ANIMAL GENETIC RESOURCES, 2000, Brasília. Proceedings... Brasília: Embrapa Genetic Resources and Biotechnology, 2000. CD-ROM.

ABREU, U. G. P.; SANTOS, S. A.; SERENO, J. R. B.; MCMANUS, C. Caracterização fenotípica e genética da precocidade sexual do bovino pantaneiro. Archivos de Zootecnia, Córdoba, v. 56, p. 627-631, 2007. Suplemento 1.

BARBOSA, A. M.; VALADARES, R. F. D.; VALADARES FILHO, S. C.; VÉRAS, R. M. L.; LEÃO, M. I.; DETMANN, E.; PAULINO, M. F.; MARCONDES, M. I.; SOUZA, M. A. Efeito do período de coleta de urina, dos níveis de concentrado e de fontes protéicas sobre a excreção de creatinina, de uréia e de derivados de purina e a produção microbiana em bovinos Nelore. Revista Brasileira de Zootecnia, Viçosa, MG, v. 35, n. 3, p. 870-877, 2006.

CABRAL, L. S.; VALADARES FILHO, S. C.; DETMANN,E.;MALAFAIA,P.A.M.;ZERVOUDAKIS, J. T.; SOUZA, A. L.; VELOSO, R. G.; NUNES, P. M. $\mathrm{M}$. Consumo e digestibilidade dos nutrientes em bovinos alimentados com dietas à base de volumosos tropicais. Revista Brasileira de Zootecnia, Viçosa, MG, v. 35, n. 6, p. 2406-2412, 2006.

CASALI, A. O.; DETMANN, E.; VALADARES FILHO, S. C.; PEREIRA, J. C.; HENRIQUES, L. T.; FREITAS, S. G.; PAULINO, M. F. Influência do tempo de incubação e do tamanho de partículas sobre os teores de compostos indigestíveis em alimentos e fezes bovinas obtidos por procedimento in situ. Revista Brasileira de Zootecnia, Viçosa, MG, v. 37, n. 2, p. 335-342, 2008.

CAVALCANTE, M. A. B.; PEREIRA, O. G.; VALADARES FILHO, S. C.; RIBEIRO, K. G. Níveis de proteína bruta em dietas para bovinos de corte: consumo, digestibilidade total e desempenho produtivo. Revista Brasileira de Zootecnia, Viçosa, MG, v. 34, n. 3, p. 711719, 2005.

CHIZZOTTI, M. L.; VALADARES FILHO, S. C.; VALADARES, R. F. D.; CHIZZOTTI, F. H. M.; TEDESCHI L. O. Determination of creatinine excretion and evaluation of spot urine sampling in Holstein cattle.
Livestock Sciences, Almsford, v. 113, n. 2-3, p. 218-225, 2008.

DETMANN, E.; QUEIROZ, A. C.; CECON, P. R.; ZERVOUDAKIS, J. T.; PAULINO, M. F.; VALADARES FILHO, S. C.; CABRAL, L. S.; LANA, R. P. Consumo de fibra em detergente neutro por bovinos em confinamento. Revista Brasileira de Zootecnia, Viçosa, MG, v. 32, n. 6, p. 1763-1777, 2003.

DIAN, P. H. M.; PRADO, I. N.; FUGITA, C. A.; PRADO, R. M.; VALERO, M. V.; BERTIPAGLIA, L. M. A. Substituição do milho pelo resíduo de fecularia de mandioca sobre o desempenho, digestibilidade e características de carcaça de novilhos confinados. Acta Scientiarum. Animal Sciences, Maringá, v. 31, n. 4, p. 381-387, 2009.

FATURI, C.; EZEQUIEL, J. M. B.; FONTES, N. A.; STIAQUE, M. G.; SILVA, O. G. C. Fibra solúvel e amido como fontes de carboidratos para terminação de novilhos em confinamento. Revista Brasileira de Zootecnia, Viçosa, MG, v. 35, n. 5, p. 2110-2117, 2006.

FRANZOLIN, R.; SILVA, J. R.; OCAMPOS, D. Níveis de energia na dieta para bubalinos em crescimento alimentados em confinamento. 1. Desempenho e bioquímica de nutrientes sanguíneos. Revista Brasileira de Zootecnia, Viçosa, MG, v. 30, n. 6, p. 1872-1879, 2001.

ÍTAVO, L. C. V; VALADARES FILHO, S. C.; SILVA, F. F.; VALADARES, R. F. D.; CECON, P. R.; ÍTAVO, C. C. B. F.; MORAES, E. H. B. K.; PAULINO, P. V. R. Níveis de concentrado e proteína bruta na dieta de bovinos nelore nas fases de recria e terminação: consumo e digestibilidade. Revista Brasileira de Zootecnia, Viçosa, MG, v. 31, n. 2, p. 1033-1041, 2002. Suplemento.

JULIANO, R. S.; RAMOS, A. F.; SANTOS, S. A.; ABREU, U. G. P. Análise de características reprodutivas indicadoras de puberdade em tourinhos Pantaneiro. Archivos de Zootecnia, Córdoba, v. 60, n. 231, p. 3253208, 2011.

MARQUES, K. A. Comportamento ingestivo, consumo e digestibilidade de bovinos e búfalos alimentados com níveis crescentes de concentrado. 2008. Dissertação (Mestrado em Zootecnia) - Universidade Federal Rural de Pernambuco, Recife.

MAZZA, M. C. M.; MAZZA, C. A.; SERENO, J. R. B.; SANTOS, S. A. L.; PELLEGRIN, A. O. Etnobiologia e conservação do bovino Pantaneiro. Corumbá: EMBRAPA-CPAP, Corumbá; Brasília: EMBRAPA-SPI, 1994. $61 \mathrm{p}$.

MAZZA, M. C. M.; MAZZA, C. A. S.; SERENO, J. R. B.; SANTOS, S. A. L.; MARIANTE, A. S. Conservation 
of Pantaneiro cattle in Brazil. Historical origin. Archivos de Zootecnia, Córdoba, v. 41, n. 154, p. 443-453, 1992.

MERTENS, D. R. Análise da fibra e sua utilização na avaliação e formulação de rações. In: SIMPÓSIO INTERNACIONAL DE RUMINANTES. REUNIÃO ANUAL DA SOCIEDADE BRASILEIRA DE ZOOTECNIA, 29., 1992, Lavras. Anais... Lavras: SBZ, 1992. p. 188-219.

OLIVEIRA, M. V. M. O.; LANA, R. P.; FREITAS, A. W. P.; EIFERT, E. C.; PEREIRA, J. C.; VALADARES FILHO, S. C.; PÉREZ, J. R. O. Parâmetros ruminal, sanguíneo e urinário e digestibilidade de nutrientes em novilhas leiteiras recebendo diferentes níveis de monensina. Revista Brasileira de Zootecnia, Viçosa, MG, v. 34, n. 6, p. 2143-2154, 2005.

PEREIRA, M. L. A.; VALADARES FILHO, S. C.; VALADARES, R. F. D.; CAMPOS, J. M. S.; LEÃO, M. I.; PEREIRA, C. A. R.; SILVA, P. A.; MENDONÇA, S. S. Consumo, digestibilidade aparente total, produção e composição do leite em vacas no terço médio da lactação alimentadas com níveis crescentes de proteína bruta no concentrado. Revista Brasieira de Zootecnia, Viçosa, MG, v. 34, n. 3, p. 1040-1050, 2005.

RENNÓ, L. N. Consumo, digestibilidade total e parcial, produção microbiana, parâmetros ruminais e excreções de uréia e creatinina em novilhos alimentados com dietas contendo quatro níveis de uréia ou dois níveis de proteína. 2003. Tese (Doutorado em Zootecnia) Universidade Federal de Viçosa, Viçosa, MG.

RENNÓ, L. N.; VALADARES FILHO, S. C.; PAULINO, M. F.; LEÃO, M. I.; VALADARES, R. F. D.; RENNÓ, F. P.; PAIXÃO, M. L. Níveis de uréia na ração de novilhos de quatro grupos genéticos: parâmetros ruminais, uréia plasmática e excreções de uréia e creatinina. Revista Brasileira de Zootecnia, Viçosa, MG, v. 37, n. 3, p. 556562, 2008.

RIBEIRO, K. G.; GARCIA, R.; PEREIRA, O. G.; VALADARES FILHO, S. C.; CECON, P. R. Consumo e digestibilidades aparentes total e parcial, de nutrientes, em bovinos recebendo rações contendo feno de capimTifton 85 de diferentes idades de rebrota. Revista Brasileira de Zootecnia, Viçosa, MG, v. 30, n. 2, p. 573580, 2001.
RUBIANO, G. A. G. Desempenho, características de carne e de carcaça de bovinos jovens de quatro grupos raciais no modelo biológico superprecoce. 2006. Dissertação (Mestrado em Zootecnia) - Universidade Estadual Paulista, Botucatu.

SANTOS, S. A.; SILVA, R. A. M. S.; COMASTRI FILHO, J. A.; ABREU, U. G. P.; McMANUS, C.; MARIANTE, A. S.; LARA, M. A. C.; PELLEGRIN, A. O.; RAVAGLIA, E. Desempenho de bezerros Pantaneiros, Nelore e cruzados criados no Pantanal, Brasil. Archivos de Zootecnia, Córdoba, v. 54, n. 206-207, p. 501-508, 2005.

SERENO, J. R. B. Uso potencial do bovino pantaneiro na produção de carne orgânica do pantanal. In: CONFERÊNCIA VIRTUAL GLOBAL SOBRE PRODUÇÃO ORGÂNICA DE BOVINOS DE CORTE, 1., 2002, Concórdia. Anais... Concordia: EMBRAPA, 2002. Disponível em: <http://www.cpap.embrapa.br/ agencia/congressovirtual/pdf/portugues/06pt04.pdf $>$. Acesso em: 29 dez. 2008.

SILVA, A. V.; PEREIRA, O. G.; VALADARES FILHO, S. C.; GARCIA, R.; CECON, P. R.; FERREIRA, C. L. L. F. Consumo e digestibilidades dos nutrientes em bovinos recebendo dietas contendo silagens de milho e sorgo, com e sem inoculante microbiano. Revista Brasileira de Zootecnia, Viçosa, MG, v. 35, n. 6, p. 2469-2478, 2006.

SILVA, R. R.; PRADO, I. N.; CARVALHO, G. G. P.; SILVA, F. F.; SANTANA JUNIOR, H. A.; SOUZA, D. R.; DIAS, D. L. S.; PEREIRA, M. M.; MARQUES, J. A.; PAIXÃO, M. L. Novilhos Nelore suplementados em pastagens: Consumo, desempenho e digestibilidade. Archivos de Zootecnia, Córdoba, v. 59, n. 228, p. 549560, 2010.

SNIFFEN, C. J.; O'CONNOR, J. D.; VAN SOEST, P. J.; FOX, D. G.; RUSSEL, J. B. A net carbohydrate and protein system for evaluating cattle diets. II. Carbohydrate and protein availability. Journal of Animal Science, Champaign, v. 70, n. 11, p. 3562-3577, 1992.

TEODORO,A.L.Desempenho, comportamento ingestivo e digestibilidade em novilhas da raça "Pantaneira", sob dietas com diferentes niveis protéicos. 2011. Dissertação (Mestrado em Zootecnia) - Universidade Federal da Grande Dourados, Dourados. 